\section{Os cirurgiões-dentistas e as representações sociais da Aids}

\author{
The dental surgeons and \\ the Aids social representations
}

M aísa Paulino Rodrigues 1

M oisés Domingos Sobrinho 2

Edna M aria da Silva 3

1 Programa de

Pós-Graduação em O dontologia Social, UFRN. Av. Salgado Filho 1.787, Lagoa N ova,

59056-000, Natal RN. maisapaulino@digi.com.br

2 Programa de

Pós-Graduação em Educação, UFRN .

3 Programa de

Pós-Graduação em

Odontologia Social, UFRN.
Abstract This study tried to know the social representation of Aids which is developed by the dental surgeons of the city of $\mathrm{N}$ atal, Brazil. The center of analysis comprises 100 dental surgeons, and is based on the theories of social representations. A questionnaire was applied with them, there were al so semi-structured interviews and etnografhic feature observation technique was developed. The findings indicate that the dental surgeons were informed about the contamination modalities, as well as the means for risk prevention. In spite of this, knowledge was incomplete, fragmented and based on an old-fashioned and traditional view of biosafety, which hampers the development of strategies to overcome the traditional practices. A mix of fear, threats, ambivalences has been introjecting in the social representations of this phenomenon. This mechanism hinders the structuring of behaviors, as well as, real actions towards prevention. Thus, it is necessary to develop new estrategies that can give a new signification the phenomenon, and at the same time, take into account the whole set of mental elaborations, emotions, daily practical and explanatory theories which are introduced in the constitution of social representation, under study, and that acts concretely by influencing the choices and before the risk of Aids contamination and transmission. Key words Aids, Social Representations, Prevention
Resumo N este estudo, procu rou-se conhecer a representação social da Aids construída pelos cirurgi ões-dentistas da cidade do $\mathrm{N}$ atal. $\mathrm{O}$ foco de análise foi dirigido para 100 cirurgiões-dentistas, tomando como base a teoria das representações sociais. Foi aplicado um questionário, realizadas entrevistas semi-estruturadas e desenvolvida a técnica da observação de cunho etnográfico. As conclusões indicam que os cirurgiões-dentistas se apresentam informados sobre as formas de contaminação e os meios de prevenção de riscos; entretanto, demonstram um conhecimento incompleto, fragmentado e amparado por uma visão tradicional e superada de biossegurança, o que dificulta o desenvolvimento de estratégias de superação das práticas tradicionais. U ma mistura de medo, ameaças, ambivalências vai se introjetando nas representações sociais desse fenômeno. Esse mecanismo dificulta a estruturação de condutas ou ações preventivas. Assim, faz-se necessário desenvolver diferentes estratégias visando ressignificar o fenômeno e, ao mesmo tempo, levar em conta todo o conjunto de elaborações mentais, emoções, teorias práticas e explicativas do cotidiano, que se introduzem na constituição da representação social em questão e agem concretamente influenciando as escolhas e alternativas elaboradas por esses sujeitos diante do risco de contaminação e transmissão da Aids.

Palavras-chave Aids, Representações Sociais, Prevenção 


\section{Introdução}

A infecção pelo vírus da imunodeficiência humana (HIV) e a ocorrência da Síndrome da Imunodeficiência Adquirida (Sida ou Aids) é, na atualidade, um dos maiores desafios colocados para a ciência nesta transição de milênio. Constitui-se numa epidemia que atinge uma grande quantidade de países, tanto do "primeiro mundo" quanto dos mais pobres, com conseqüências em diversas dimensões sociais, tais como a saúde, a cultura, a política, a economia e a ética.

Como para outras áreas da saúde, a epidemia da Aids trouxe também alguns desafios importantes para o setor da odontologia. 0 primeiro deles foi o de obrigar esse setor a traçar um desenho mais preciso a respeito das práticas de prevenção de riscos de contaminação adotadas pelos cirurgiões-dentistas durante o desempenho de suas funções. Em seguida, foi necessário estudar a prática cotidiana desses profissionais, para conhecer as percepções, os significados e as crenças que podem facilitar ou dificultar a adoção de condutas mais adequadas relativas às medidas de biossegurança $e$ para reduzir o risco de infecção cruzada dentro do consultório odontológico.

A partir da década de 1980, com a emergência da síndrome Aids, tiveram início às primeiras discussões e os primeiros estudos sobre a biossegurança em odontologia, fazendo despertar uma consciência maior por parte das comunidades de saúde sobre o perigo da transmissão ocupacional de agentes infecciosos. A descoberta da Aids provocou um avanço na adoção de medidas de biossegurança e o assunto se tornou alvo das preocupações da prática médico-odontológica (Cottone \& M olinari, 1991).

No Brasil, em meados da década de 1980, começaram a ser publicados os primeiros trabal hos relacionados ao controle de infecção na área odontológica. D entre eles, destaca-se o estudo de Rossetini (1985), que evidenciou os problemas relativos ao contágio no consultório odontológico, salientando as evidências do ris$\mathrm{CO}$, as vias de transmissão e as medidas recomendadas para redução do risco de contaminação.

Diante dessa nova realidade, o M inistério da Saúde passou a orientar que a estruturação dos serviços de assistência odontológica, para al cançar amplo impacto social, caracterizado pelo controle de infecção na sua prática, deve ser tratada no âmbito da reforma sanitária, de conformidade com o disposto na Constituição Brasileira, seção II, e nas leis federais 8.080 de 19/09/90 e 8.142 de 28/12/90 (Brasil,1992).

A Aids vem ganhando grandes proporções e causando muita preocupação em nível mundial. Os dentistas, conscientes ou não, estão envolvidos nessa pandemia, na medida em que atendem inúmeros pacientes, entre eles portadores assintomáticos do vírus HIV. As infecções causadas por esse vírus podem provocar uma quantidade considerável de sintomas, entre os quais as manifestações bucais exercem um papel importante, pois, além de serem muito comuns, estão geralmente entre as queixas principais dos pacientes e se apresentam como primeiros sinais e sintomas dessa doença. Entre as manifestações bucais de pacientes com o HIV, encontram-se as doenças periodontais, infecções oportunísticas (herpes e candidíase), leucoplasia pilosa, neoplasias-sarcoma de Kaposi, linfoma e outras (Silverman, 1991; Ceccoti, 1993).

Dentre os vários riscos a que estão sujeitos os profissionais de saúde, particularmente o cirurgião-dentista, está o risco de infecção através da transmissão de agentes infecciosos dentro do ambiente clínico. Essa infecção pode ocorrer pelo ar, pelo contato pessoa-pessoa, ou ainda por meio de objetos contaminados. Embora o problema - como, por exemplo, infecções pós-cirúrgicas, transmissão de hepatite $B(\mathrm{HBV})$, herpes simples (HVS) etc. - sempre tenha ocorrido, os profissionais de odontologia, por sua vez, nem sempre estiveram conscientes dos passos necessários para eliminar ou diminuir os riscos para os pacientes e para si próprios.

Faz-se necessário, portanto, que os profissionais realizem um exame bucal completo e criterioso em todos os pacientes, o que possibilitará a identificação de pacientes de risco. Em pacientes HIV positivos ou com Aids, éimprescindível diagnosticar o estágio da doença, para indicação da terapêutica necessária. Acreditase que a maioria dos procedimentos odontológicos restauradores pode ser executada nesses pacientes por qualquer clínico generalista e, na necessidade de encaminhamento para especialistas, os critérios devem ser os mesmos utilizados para quaisquer outros pacientes (Greenspan \& Greenspan, 1991).

Como medidas preventivas básicas e fundamentais, tem-se o uso de Equipamento de Proteção Individual (EPI), a utilização de técnicas corretas de desinfecção e esterilização, a 
observância de processos apropriados de isolamento, gerenciamento dos resíduos, constante higiene das mãos, vacinação, entre outros.

0 fenômeno da Aids/biossegurança mobiliza, no campo da odontologia, particularmente, um complexo de significações e relações que somente podem ser entendidos partindo-se da contextualização dos aspectos sócio-históricoculturais que o produzem. Sendo assim, considerou-se aqui a complexidade do objeto em questão, pondo em evidência a diversidade de práticas e realidades dos sujeitos, as diferentes significações da Aids/biossegurança e as relações contraditórias que envolvem essa produção de sentidos, a fim de se poder, ao final, fornecer subsídios para a elaboração de novas estratégias de enfrentamento dos problemas e riscos decorrentes das práticas que ain da não incorporam as medidas de biossegurança.

Assim, conhecer as representações sociais da Aids, e conseqüentemente, da biossegurança, é conhecer a maneira pela qual esse fenômeno é percebido, ou seja, é compreender como as representações desse objeto são vivenciadas individual mente e pelos diferentes grupos de cirurgiões-dentistas.

Desde a sua concep ção na década de 1960 , a teoria das representações sociais vem sendo utilizada em pesquisas nas diversas áreas do saber. Cabe ressaltar, ainda, que essa teoria tem sido largamente empregada em diversas pesquisas no campo da saúde, para o estudo dos fenômenos sociais que permeiam o processo saúde-doença, a partir da análise de percepções cotidianas individuais/grupais (Flick, 1992).

É notável o valor do estudo das representações sociais para a compreensão de atitudes e práticas com relação à Aids, tal abordagem ... parece ser particularmente útil para a análise, a compreensão e a intervenção sobre os grandes problemas sociais atuais: a saúde e a doença e, em particular, a disseminação da Aids; a exclusão e os problemas de integração das minorias ou grupos sociais desviantes; a crise da ideologia e 0 desenvolvimento de crenças mágicas ou religiosas; a crise econômica e aumento do desemprego etc. (Abric, 1996).

A utilização e o interesse pelos estudos plurimetodológicos em saúde ganhou proporções a partir do momento em que o desenho dos métodos tradicionais de pesquisa apresentou possibilidades limitadas de dar respostas a determinadas questões propostas por pesquisadores ou a demandas dos serviços (Llovet \& Ramos, 1995).
Nesse sentido, observa-se a necessi dade da adoção de novos referenciais e novas metodologias, na perspectiva de se obterem modelos explicativos úteis ao diagnóstico de situações socioculturais, os quais possibilitem intervenções eficazes, senão no controle, pelo menos na prevenção da infecção pelo HIV.

A metodologia e os instrumentos utilizados para o estudo de representações sociais são bastante apropriados para tais investigações. Ou seja, tais instrumentos podem possibilitar a expressão de conteúdos subjetivos que fluem em decorrência do modo como se formulam perguntas, ou até mesmo do inusitado das situações propostas, tais como as associações livres de palavras ou testes projetivos a partir de sinais ambíguos ou incompletos. Entretanto, é necessário que o pesquisador se posicione de forma a possibilitar a expressão autêntica das diversas realidades subjetivas, tal como se mostra a vida social, em constante elaboração (Souza Filho, 1998).

0 propósito principal deste estudo foi o de identificar as representações sociais construídas pel os cirurgiões-dentistas acerca da Aids, bem como verificar como essas representações vêm orientando as práticas desses sujeitos, em relação às medidas de biossegurança.

\section{Metodologia}

Considerando-se que a linguagem exerce uma função preponderante na formação e na circulação das representações, procurou-se captar os discursos produzidos pel os cirurgiões-dentistas a respeito da Aids, de modo a se poder apreender as representações sociais por el es construídas e, dessa forma, perceber como el as orientam a sua prática odontológica. U tilizamos, então, um questionário estruturado de forma convencional, de entrevistas semi-estruturadas e da observação de cunho etnográfico.

0 foco da observação foi dirigido a cem cirurgiões-dentistas com tempo de exercício profissional variando de 1 a 35 anos, todos vinculados ao serviço de saúde pública da cidade do $N$ atal (em grande parte, vinculados também à iniciativa privada), distribuídos pelas diferentes regiões geográficas do município e trabaIhando em especialidades diversas. Os sujeitos foram selecionados entre os aproximadamente 230 (duzentos e trinta) participantes do Seminário sobre Câncer e Saúde Bucal realizado pela Secretaria da Saúde Pública do Rio Grande do Norte, em julho de 2000. 
O trabalho de campo foi dividido em duas fases: a primeira correspondeu à aplicação do questionário e na segunda foram realizadas as entrevistas e a observação de cunho etnográfico.

0 questionário continha perguntas fechadas a respeito da transmissão de doenças dentro do consultório odontológico, estratégias de prevenção, atendimento a pacientes portadores do HIV ou Aids e sobre a utilização de procedimentos diferenciados para 0 atendimento a esses pacientes.

As entrevistas foram orientadas pela seguinte questão: Você já atendeu algum paciente portador do vírus HIV ou com Aids? Se soubesse que o paciente era portador, utilizaria alguma medida diferente das utilizadas no dia-a-dia?

A observação de cunho etnográfico foi utilizada visando-se observar como os conteúdos representacionais, enquanto vinculados a universos simbólicos mais amplos, orientam, na prática, as ações dos sujeitos, permitindo, assim, confrontar os discursos e as práticas cotidianas no consultório odontológico. Essa técnica, como diz M inayo (1996), aplicada diretamente à própria realidade, permite captar 0 que há de mais imponderável e evasivo na vida real. Esse tipo de observação foi realizado antes de cada entrevista.

Pôde-se, dessa forma, constatar as várias "contradições" entre o dizer e o fazer, evidenciando o que Moscovici (1989) denominou de "polifasias cognitivas", ou seja, a ausência de coerência de um saber que, diferentemente do saber científico ou especializado, é obrigado, no dia-a-dia, a articular informações, noções, concepções, enfim uma gama de elementos contraditórios, a fim de construir um sentido para os objetos do mundo circundante. Foi, portanto, através desses passos metodológicos, que buscamos uma aproximação ao universo de vida dos sujeitos, procurando identificar suas representações sobre Aids/biossegurança.

Alguns pressupostos teóricos foram tomados como base para a análise. Por um lado, o de que as práticas discursivas acontecem em vários tempos de circulação das idéias na sociedade. 0 tempo histórico e o tempo vivido articulam a experiência no contexto cultural e social, permitindo revelar os repertórios de diversas épocas e aqueles derivados da vivência em determinados grupos. Eles criam o contexto para entender o tempo presente, que é a ênfase na funcionalidade na esfera da intersubjeti vidade que permite postular que, para entender a pro- cessualidade intrínseca da atividade de significação é preciso focalizar as rupturas (Spink \& Gimenez, 1994).

Por outro lado, partimos, também, do pressuposto de que, na análise das produções discursivas, é preciso considerar que o discurso é intersubjetivo, portanto faz-se necessário entender a interface criada na interação entre o entrevistado e o entrevistador. Considerar os repertórios lingüísticos e sua variabilidade é condição fundamental no momento da análise.

$\mathrm{H}$ á, primeiramente as associações de idéias presentes quando o objeto é referido. Mas há, também, indicadores lingüísticos, como a ambigüidade (múltiplos significados); a contradição (sentidos antagônicos); a inconsistência (significados instáveis) e a incoerência (a transgressão das regras lógicas de uma narrativa que sugere a adoção de outra narrativa). Há que se considerar, ainda, a busca da argumentação e da deposição de valores: os qualificadores reveladores do investimento afetivo (Spink \& Gimenes, 1994).

As representações sociais são entendidas como teorias compartilhadas pelo grupo que serve de referência - nesse caso, os cirurgiõesdentistas. Dessa forma, buscamos compreender a construção compartilhada que forma o senso comum desse grupo. Por fim, a interpretação dos dados considerou todo o corpus obtido através dos métodos qualitativo e quantitativo aqui empregados e a respectiva combinação de técnicas utilizadas.

\section{Resultados e discussão}

Entre os profissionais que participaram da pesquisa, $69 \%$ eram do sexo feminino e $31 \%$ do sexo masculino. A faixa etária variou entre 21 a 65 anos de idade, sendo que $32 \%$ tinham até 35 anos, $60 \%$ estavam na faixa etária entre 36 e 50 anos e $8 \%$ possuíam idade acima de 50 anos.

A análise das informações contidas no quadrol deixa claro que os cirurgiões- dentistas encontram-se informados sobre as doenças que podem ser veiculadas e adquiridas durante a prática profissional. 0 mesmo pode ser constatado na análise da tabela 1.

Como se percebe, apenas dois sujeitos acreditam que não há possibilidade de se prevenirem das doenças a que se encontram expostos durante a realização dos procedimentos odontológicos, o que faz sugerir que não acreditam ou desconhecem as barreiras efetivas para o controle de infecção. Outros seis profissionais 
disseram não acreditar que o consultório odontológico pudesse vir a ser um veículo de transmissão de doenças para os pacientes, o que pode levar à compreensão da existência de um rigoroso controle de infecção ou, ainda, da crença de que as doenças não se transmitem tão facilmente, como pode ser observado através do discurso de um desses sujeitos: ... mas graças a Deus essas... essas... essas coi sas não... não pegam assim como a gente imagina, deveria... se pegasse... o negócio seria muito cruel (CD 5, M, 50 anos). [CD = cirurgião-dentista, seguido do número de identificação, sexo e idade]

Ao desconhecimento (ou não-aceitação) de informações científicas atualizadas, sobrepõese o imaginário religioso, o apelo a uma força maior, capaz de evitar a contaminação por doenças infectocontagiosas. Essa constatação é, pois, importante para as estratégias de controle de infecção e biossegurança.

A Aids, na qualidade de objeto de representação simbólica, gera condutas divergentes e obscuras. Avaliando-se as possíveis relações dos sujeitos, em caso de atendimento a pacientes portadores do HIV, percebem-se muitas confusões e ambivalências quanto ao que deve ser a conduta correta, tanto em relação às medidas de controle de infecção quanto ao acolhimento do paciente.

A tabela 2 apresenta o resultado das respostas relativas à questão: Você atenderia um paciente que estivesse, comprovadamente, com o vírus HIV ou com Aids?

Os resultados evidenciam aspectos interessantes. Por exemplo: 68 profissionais afirmaram que atenderiam a pacientes soropositivos para o HIV, ao mesmo tempo em que 29 afirmaram não atender a paciente com Aids, por

\section{Quadro 1}

Distribuição das doenças que podem ser contraídas durante o exercício profissional segundo a percepção dos cirurgiões-dentistas. Natal, RN-2000.

\begin{tabular}{|c|c|c|}
\hline Doenças & $f$ & $\%$ \\
\hline Aids & 81 & $81 \%$ \\
\hline Anemia & 1 & $1 \%$ \\
\hline Artrite & 1 & $1 \%$ \\
\hline Câncer & 1 & $1 \%$ \\
\hline
\end{tabular}

Câncer

Conjuntivite

Contaminação por

$1 \%$

agentes químicos

DST

Doenças de pele

Doença infectocontagiosa

Doenças pulmonares

Deficiência auditiva

Gripe

Hepatite

Herpes

Hemorróidas

HPV

Impotência sexual

Infecções

LER

Leucemia

Morte

Perda de memória

Piolho

Pneumonia

Problema de coluna

Psiconeurose

Reumatismo

Sífilis

Sinusite

Tuberculose

1

10

1

$10 \%$

$1 \%$

Varizes

Viroses

\begin{tabular}{rr}
4 & $4 \%$ \\
3 & $3 \%$ \\
10 & $10 \%$ \\
1 & $1 \%$ \\
5 & $5 \%$ \\
34 & $34 \%$ \\
89 & $89 \%$ \\
23 & $23 \%$ \\
1 & $1 \%$ \\
1 & $1 \%$ \\
1 & $1 \%$ \\
2 & $2 \%$ \\
2 & $2 \%$ \\
1 & $1 \%$ \\
1 & $1 \%$ \\
1 & $1 \%$ \\
2 & $2 \%$ \\
2 & $2 \%$ \\
6 & $6 \%$ \\
1 & $1 \%$ \\
2 & $2 \%$ \\
10 & $10 \%$ \\
1 & $1 \%$ \\
23 & $23 \%$ \\
1 & $1 \%$ \\
13 & $13 \%$ \\
2 & $2 \%$ \\
\hline &
\end{tabular}

Ausência de saúde financeira

\section{Tabela 1}

Cirurgiões- dentistas segundo a compreensão sobre contaminação e prevenção de doenças infectocontagiosas no exercício da profissão. N atal, RN-2000.

\begin{tabular}{lccc}
\hline Questões & Sim & Não & Não sei \\
\hline $\begin{array}{l}\text { O CD está sujeito a contrair doenças } \\
\text { durante o atendimento? Quais? }\end{array}$ & 100 & - & - \\
\hline $\begin{array}{l}\text { O CD pode se prevenir contra as doenças } \\
\text { a que está exposto durante o atendimento? }\end{array}$ & 98 & 2 & - \\
\hline $\begin{array}{l}\text { O consultório pode ser um veículo de } \\
\text { transmissão de doenças para os pacientes? }\end{array}$ & 94 & 6 & - \\
\hline
\end{tabular}


Tabela 2

Cirurgiões-dentistas segundo o tempo de exercício profissional e 0 atendimento ao paciente com Aids. Natal, RN-2000.

\begin{tabular}{lcccc}
\hline $\begin{array}{l}\text { Tempo de exercício } \\
\text { profissional }\end{array}$ & $\begin{array}{c}\text { Número de } \\
\text { profissionais }\end{array}$ & Sim & Não & Não sei \\
\hline 1 a 10 anos & 28 & 17 & 11 & - \\
11 a 20 anos & 50 & 35 & 12 & 3 \\
21 a 30 anos & 22 & 16 & 6 & - \\
Total & $\mathbf{1 0 0}$ & $\mathbf{6 8}$ & $\mathbf{2 9}$ & $\mathbf{3}$ \\
\hline
\end{tabular}

não se sentirem preparados; três responderam que não sabiam se prestariam 0 atendimento. Entre os que declararam o não-atendimento, as razões al egadas foram: falta de informação sobre o tema, falta de condições psicológicas, falta de condições de biossegurança no local de trabalho, entendimento de que esse tipo de paciente deve receber tratamento em local especializado, havendo também quem admita o preconceito para com o paciente. U $\mathrm{m}$ fato que chama a atenção é que, entre os 68 (100\%) que afirmaram atender ao paciente portador do vírus, $57(83,8 \%)$ responderam que utilizariam procedimentos especiais para tal atendimento (Tabela 3).

A tabela 3 refere-se ao resultado das respostas da seguinte questão: $\mathrm{Em}$ caso de atendimento ao paciente portador do vírus HIV ou com Aids, você utilizaria algum procedimento especial?

Ao se associar o desempenho dos dentistas com a idade e, conseqüentemente, com o tempo de exercício profissional, observou-se que os mais jovens, ou seja, aqueles com até 10 anos de profissão, são os que cometem mais erros: $100 \%$ declararam que utilizariam procedimentos diferenciados (especial) para atender um paciente com Aids. Para facilitar a análise desse cruzamento de variáveis, foi utilizado o critério de adotar como acerto à não-adoção de procedimento especial (diferenciado) no atendimento ao paciente com HIV e, como erro, a adoção de procedimento especial, partindo-se, pois, da concepção de que todo paciente deva ser considerado como potencialmente infectado, portanto devendo ser tratado com os mesmos cuidados e de forma padronizada (Tabela 4).

Era de se esperar um desempenho mais favorável dos mais jovens, uma vez que esses sujeitos concluíram sua formação profissional mais recentemente, supondo-se, assim, um maior acesso às informações, discussões e conhecimentos atualizados sobre o tema. Cabe ressaltar, ainda, que esses profissionais estão entre os que têm menor percentual de conhecimento sobre o tema em questão, ou seja, apenas $28,5 \%$ informaram possuir algum treinamento ou curso sobre biossegurança, apesar de todos (100\%) estarem inseridos no serviço público de saúde.

Os profissionais com tempo de exercício profissional entre 11 e 20 anos estão entre os que cometem menos erros sobre o procedimento correto, ou seja: $25,7 \%$ afirmaram que não seriam necessárias medidas especiais ou diferenciadas para atender ao paciente portador do vírus HIV, compreendendo que todo paciente deve ser considerado potencialmente infectado. Isso provavelmente se relaciona ao fato de esses sujeitos estarem em plena atividade profissional, supondo-se investimentos em cursos, capacitações, congressos, entre outros, o que certamente contribui para elevar o nível de informação.

Entre os que apresentavam mais de 20 anos de exercício profissional, o desempenho positivo ficou em torno de $12,5 \%$, o que pode ser considerado baixo. Os profissionais pertencentes a essa faixa etária provavelmente estão próximos à aposentadoria, podendo, assim, haver desestímulo em relação ao investimento na profissão e, conseqüentemente, um desempenho menos satisfatório.

Em geral, os sujeitos apresentaram um desempenho que pode ser considerado inadequado para o desenvolvimento de atitudes ou práticas positivas para a prevenção das doenças e controle de infecções. É importante ressaltar que somente $16,1 \%$ dos profissionais apresentaram um desempenho satisfatório em relação ao tema, como os citados a seguir:

... devemos atender todos os pacientes com os mesmos cuidados com a biossegurança, devemos considerar todo paciente como paciente de risco. (CD 92, F, 38anos) 
Tabela 3

Cirurgiões-dentistas segundo o tempo de exercício profissional e a predisposição para utilizar ou não procedimento especial no atendimento ao paciente com Aids. N atal, RN-2000.

\begin{tabular}{lccc}
\hline $\begin{array}{l}\text { Tempo de exercício } \\
\text { profissional }\end{array}$ & Executa atendimento & $\begin{array}{c}\text { Utiliza } \\
\text { procedimento especial }\end{array}$ & $\begin{array}{c}\text { Não utiliza } \\
\text { procedimento especial }\end{array}$ \\
\hline 1 a 10 anos & 17 & 17 & - \\
11 a 20 anos & 35 & 26 & 9 \\
21 a 30 anos & 16 & 14 & 2 \\
Total & $\mathbf{6 8}$ & $\mathbf{5 7}$ & $\mathbf{1 1}$ \\
\hline
\end{tabular}

Tabela 4

Cirurgiões-dentistas segundo o tempo de exercício profissional e o desempenho relativo ao atendimento do paciente com Aids. N atal, RN-2000.

\begin{tabular}{lcccrr}
\hline $\begin{array}{l}\text { Tempo de exercício } \\
\text { profissional }\end{array}$ & Executa atendimento & $\begin{array}{c}\text { Utiliza } \\
\text { procedimento especial }\end{array}$ & $\begin{array}{c}\text { Não utiliza } \\
\text { procedimento especial }\end{array}$ & $\%$ Acertos & $\%$ Erros \\
\hline 1 a 10 anos & 17 & 17 & - & - & $100 \%$ \\
11 a 20 anos & 35 & 26 & 9 & $25,7 \%$ & $74,3 \%$ \\
21 a 30 anos & 16 & 14 & 2 & $12,5 \%$ & $87,5 \%$ \\
Total & $\mathbf{6 8}$ & $\mathbf{5 7}$ & $\mathbf{1 1}$ & $\mathbf{1 6 , 1 \%}$ & $\mathbf{8 3 , 9 \%}$ \\
\hline
\end{tabular}

... usaria todos os equipamentos de proteção que uso com qualquer paciente e os cuidados deveriam ser os mesmos. (CD 14, F, 39anos)

A pesquisa indicou também que $32 \%$ dos entrevistados apresentaram resistência em atender pacientes HIV positivos. Em primeiro lugar, a justificativa mais utilizada estava relacionada à falta de informação (37,9\%). Esse argumento foi também detectado por Ayer et al. (1988) e Lloyd et al. (1995), apesar de os resultadosindicarem uma freqüência satisfatória dos profissionais em cursos de biossegurança e controle de infecções. Em segundo lugar, 24,1\% alegaram a falta de condições psicológicas, argumento também encontrado na literatura internacional, para o não-atendimento ao indivíduo HIV positivo (Gerbert, 1987; H ardie, 1987; Cohen \& Grace, 1989 e 1990; Solomon et al., 1991; Bennet et al., 1995; Kress et al., 1995; M cCarthy et al.,1995 apud Leite 1996).

Outros argumentos utilizados para o nãoatendimento ao indivíduo HIV positivo relacionavam-se à falta de condições de biossegurança, indicando dificuldades na obtenção e incorporação dos procedimentos e também a existência de centro de referência especializado para 0 atendimento ao paciente com Aids.
... não atenderia, pois não estou treinada para isso e meu consultório não está pronto para esse tipo de paciente. (CD 45, F, 29 anos)

... não atenderia, devido a grande demanda de pacientes. $\mathrm{N}$ ão colocaria em risco os pacientes que viriam depois (CD 41, M , 45 anos)

$\mathrm{N}$ ão existe uma conduta única para com os pacientes, demonstrando, neste caso, a dificuldade de incorporação dos conhecimentos que envolvem biossegurança versus Aids. Vejamos o que dizem estes sujeitos:

... usaria dois pares de luvas, EPI e marcaria o paciente para atender por último. (CD 93, M , 33 anos)

... teria maior cuidado na esterilização reservando o instrumental, usaria duas luvas e teria maior cautela. (CD 17, F, 36 anos)

O discurso dos cirurgiões- dentistas faz, assim, interface com as narrativas sobre biossegurança que circulam na comunidade odontológica e que são constitutivas das teorias de senso comum usadas no afã de dar sentido à prática profissional. Ilustra a concomitância de narrativas diversas. A teoria organizadora do discurso - dobraria os cuidados com as luvas para evitar o mínimo contato possível com sangue, com agulha e instrumental afiado, para não me 
ferir - mostra, na íntegra, que essa teoria éfuncional tão-somente para o profissional, cuja preocupação incide na autoproteção.

Se a representação social é um conhecimento que serve para orientar a ação dos sujeitos no mundo concreto, isso não acontece, no entanto, de modo mecânico, mas servindo como uma matriz de referência, de produções de significações para as ações no cotidiano. Assim, em alguns casos de observação direta, foi possível verificar que a prática era bastante diferente do discurso manifesto, visto que, o discurso ... principalmente as luvas, as luvas precisam ser descartáveis, não é? N ão pode reaproveitar luvas, de maneira nenhuma, a biossegurança tem que ser total. As luvas, citadas pelos profissionais como elemento imprescindível, eram ignoradas, trabal hando-se em contato direto das mãos com a saliva e todos os fluidos provenientes da cavidade bucal do paciente.

Como afirma M adeira (1999), as representações não se esgotam no manifesto e não se restringem ao falar, mas têm de ser buscadas nas relações deste com o dizer. 0 dizer, muitas vezes irrompe ou faz sentir sua presença, na sutileza dos silêncios, dos risos, das hesitações ou de outros tantos mecanismos. Foi possível constatar muitas contradições entre o dizer e o fazer, no discurso retórico, construído para convencer e influenciar a ação e a prática. Essas contradições são, no entanto, inerentes às representações sociais.

Percebem-se os esforços verbais, retóricos, dos sujeitos para nos convencer de que não são incautos, desinformados. Todavia, as justificativas apontam, mais uma vez, para a precariedade das medidas preventivas que adotam no cotidiano e denotam, com clareza, a insegurança em relação ao novo. No imaginário desses profissionais, permanece a crença de nunca haver atendido a pacientes HIV positivos, como se pode perceber:

... devido ainda não ter atendido, não sei como eu iria reagir a um paciente portador do vírus HIV ou da doença. (CD7, F, 39 anos)

... se o paciente for consciente e me colocar a par do seu problema, eu irei cuidadosamente orientar-Ihe de que existe um serviço mais adequado para lhe atender de acordo com seu quadro, que lhe confere uma debilidade orgânica, tornando-o susceptível a infecções e o mesmo deverá ser atendido e de preferência executar seu tratamento no H ospital Giselda Trigueiro - H ospital de Referência para Aids. (CD 71, F, 33 anos)
Como identificar o portador do vírus HIV se, em muitos casos, nem ele mesmo sabe de sua condição? Como distinguir, a olho nu, quem é ou não portador? É fácil, portanto, constatar o perigo ao qual estão expostos esses sujeitos.

A epidemia da Aids provocou nos seus primórdios muita perplexidade e medo pela própria precariedade de informação disponível durante muitos anos. Em seguida, diversos estudos foram realizados e disponibilizados visando desmistificar esse fantasma. Entretanto, a noção de contágio imaginário, e várias outras crenças e mitos relativos à doença continua causando pânico e provocando insegurança. Em todo caso, ainda é forte a crença de que a Aids está fora de nós. Na visão de Loyola (1994), ... a Aids é considerada uma doença distante dos informantes porque é essencialmente uma "doença do outro". Assim tanto o medo e a insegurança da Aids pelo seu caráter incurável e pelos limites da medicina, quanto a sua capacidade no controle, alia-se a ela o duplo preconceito: o de ser uma doença mortal e estar associada a comportamentos sexuais socialmente não aceitos.

De acordo com as discussões realizadas anteriormente, vimos que o paciente portador do vírus HIV ou da Aids pode ser assistido por qualquer clínico generalista para receber procedimentos odontológicos restauradores e, em caso de encaminhamento para algum especialista, os critérios de encaminhamento devem ser os mesmos adotados para qualquer outro paciente. Portanto as precauções, procedimentos e medidas de biossegurança devem ser os mesmos.

Existem na literatura três registros de profissionais que se tornaram soropositivos no exercício profissional. Entretanto isso não é justificativa para a recusa do atendimento a pacientes soropositivos ao HIV. Não se faz necessário também o uso de material ou instrumental diferenciado. No entanto são imprescindíveis cuidados e precauções para evitar a transferência da Aids aos profissionais ou a pacientes sãos, uma vez que o número de portadores do HIV vem aumentando consideravelmente. $M$ as os cuidados são todos aqueles defendidos pelas normas de biossegurança para todos os pacientes.

De acordo com documentação do M inistério da Saúde Sida/Aids (1986), medidas profiláticas devem ser adotadas no contato com agentes biológicos em geral: execução rigorosa da anamnese; exame clínico minucioso (conhecimento das manifestações bucais das do- 
enças infecciosas); uso de luvas descartáveis; uso de máscaras e materiais descartáveis; uso de óculos de proteção e jaleco; correta esterilização e desinfecção: estufa $180^{\circ}$ durante uma hora, autoclave $120^{\circ}$ durante 30 minutos, hipoclorito de sódio a $1 \%$ ou álcool $70 \%$ por meia hora cada um; peça de mão e seringa tríplice desinfectadas a cada paciente atendido; acionamento inicial da peça para eliminar resíduos, lavagem das peças com água e detergente para remoção do material aderente, envolvendo-as em gaze embebida em álcool $70 \%$ por alguns minutos; fazer uso de pelo menos dois jogos de instrumental e peça de mão; desinfecção da peça operatória; uso de campo cirúrgico; e o uso de esquemas vacinais.

\section{Considerações finais}

Diante do debate em torno da questão Aids/ biossegurança, este estudo visou fundamentalmente conhecer como os cirurgiões-dentistas da cidade do $\mathrm{N}$ atal vêm absorvendo as novas informações e construindo ou redefinindo as suas representações sobre a Aids/biossegurança. Pôde-se verificar que os cirurgiões-dentistas estão devidamente informados sobre as doenças - em especial, a Aids e as formas de contaminação e transmissão desta, bem como sobre os meios de prevenção.

Avaliando-se as possíveis reações dos sujeitos, em caso de atendimento a pacientes portadores do vírus HIV, percebeu-se que ainda existem muitas confusões e contradições quanto ao que deve ser a conduta correta, tanto em relação à aplicação de um programa de controle de infecção quanto ao acolhimento do paciente.

A análise das justificativas emitidas através dos questionários e das entrevistas revela que, embora a idéia de fazer prevenção, por meio do controle de infecção, tenha sido considerada importante, faz-se necessário apoiá-la num conceito ampliado e atualizado de biossegurança, no qual preval eça um conjunto de medidas - encadeadas e complementares - para a prevenção dos riscos durante a prática odontológica.

Os resultados indicam que qualquer campanha, curso, capacitação ou treinamento que pretenda modificar as atitudes, portanto a ação cotidiana dos cirurgiões-dentistas relativas à biossegurança, tem de priorizar a discussão sobre o tema, com vistas à re-significação de prevenção e Aids. É preciso quebrar os mitos, crenças e valores sobre as prevenções existentes na perspectiva da formação tradicional do cirurgião-dentista, o que se pode obter através do desenvolvimento de diferentes estratégias educativas, associadas a outras ações práticas, principalmente por parte do poder público.

Quando se relacionam representações e práticas sociais, pretende-se chamar a atenção para o fato de que estratégias racionais que se limitam a considerar apenas a dimensão "racional" das ações humanas não são suficientes para estimular o desenvolvimento de atitudes efetivas em relação à preven ção de doenças, e particularmente, da Aids, pois desconsideram todo o processo de elaboraç̧ões mentais, emoções, teorias práticas e explicativas do cotidiano as quais se inserem na formação das representações sociais e atuam concretamente nas escoIhas dos indivíduos diante da incerteza e ameaça que a Aids suscita.

Por fim, percebe-se que os sujeitos reconhecem que as medidas de biossegurança são fundamentais para se preservar a saúde e a vida. Se tal invariância traz à luz o reconhecimento dessas medidas como imprescindíveis, traz também a negação do valor que se constrói no fazer e ratifica a dicotomia entre teoria e prática. Faz-se, pois, necessário estar atento e conhecer os diversos aspectos que envolvem a interpretação das cognições que se mobilizam em torno da Aids/biossegurança, quando se forem fazer intervenções nesse campo. 


\section{Colaboradores}

M P Rodrigues trabalhou na concepção teórica, elaboração e redação final do texto; M Domingos Sobrinho trabalhou na concepção teórica e contribuiu na redação final do texto; eEM Silva participou na organização e execução das oficinas e na revisão bibliográfica.

\section{Referências bibliográficas}

Abric J-C 1998. A Abordagem estrutural das representações sociais, pp. 27-37. In ASP M oreira \& DC Oliveira (org.). Estudos interdisciplinares de representação social. AB, Goiânia.

Abric J-C 1996. Prefácio, p. 9. In CP SÁ. N úcleo central das representações sociais. Vozes, Petrópolis.

Ayer W, M oretti R \& Derefinko A 1988. Dentist's attitudes and experience regarding the treatment of HIV - infected patients. Journal of Dental Research 67:256-259 (Special Issue).

Brasil 1992. Decreto-lei no 8.080, 19 de setembro de 1990. Dispõe sobre as condições para a remoção, proteção e recuperação da saúde, a organização e o funcionamento dos serviços correspondentes e dá outras providências. Publicações Técnicas 2, Brasília.

Brasil 1994. M inistério da Saúde. Secretaria de Assistência à Saúde. Programa Nacional de DST/AIDS. M anual hepatite, AIDS e herpes na prática odontológica. M inistério da Saúde, Brasília.

Cecotti EL 1993. Clínica estomatológica: SIDA, câncer y otras afecciones. Editorial M édica Panamericana, Buenos Aires.

Cottone JA \& M olinari JA 1991. State of the art infection control in Dentistry. Journal of the American Dental Association 123(8):33-34.

Flick U 1992. La perception quotidienne de la Santé et de la maladie. Théories Subjectives et représentations Sociales. L' H armattan, Paris.

Greenspan D \& Greenspan JS 1991. M anagement of the oral lesions of HIV infection. Journal of the American Dental Association 122:26-32.

Jodelet D 1989. Représentations sociales: un domaine en expansion, pp. 31-60. In D Jodelet (ed.). Les représentations sociales. PUF, Paris.

Leite M EA 1996. Caracterização da conduta dos cirurgiõesdentistas de Belo $\mathrm{H}$ orizonte frente aos procedimentos de controle de infecção cruzada: uma perspectiva epidemiológica. Dissertação de mestrado em Ciências Biológicas. Universidade Federal de M inas Gerais. Belo Horizonte.

Llovet JR \& Ramos S 1995. Hacia unas ciencias sociales com la medicina: obstáculos y promesas, pp. 43-72. In E H ardy, MJD Osis \& ER Crespo (org.). Ciências sociais e medicina: atualidades e perspectivas latinoamericanas. CEICAM P, Campinas.
Lloyd L, Burke FJT \& Cheung SW 1995. H andpiece assepsis: a survey of the attitudes of dental practitioners. British Dental Journal 178:23-27.

Loyola M A 1994. Aids e prevenção da Aids no Rio de Janeiro, pp. 72-79. In M A Loyola. Aids e sexualidade: 0 ponto de vista das ciências humanas. Relume-Dumará, Rio de Janeiro.

M adeira M C 1991. Representações sociais: pressupostose implicações. Revista Brasileira de Estudos Pedagógicos 71(171):129-144.

M adeira M C 1991. Representação social, racionalidade e linguagem. UFRN/NEPERS, (mimeo).

M inayo M CS 1994 (org.). Pesquisa social: teoria, método e criatividade. Vozes, Petrópolis.

M inayo M CS 1996. 0 desafio do conhecimento: pesquisa qualitativa em saúde. (4ạ ed.). Hucitec-Abrasco, São Paulo-Rio de Janeiro.

Moreira ASP \& M oriya TM 1998. Aspectos psicossociais da epilepsia: representações sociais intergrupos, pp. 205-214. In ASP M oreira \& DC Oliveira (org.). Estudos interdisciplinares de representação social. AB, Goiânia.

M oscovici S 1978. A representação social da psicanálise. Zahar, Rio de Janeiro.

M oscovici S 1989. Prefácio. In D Jodelet. Folies et representations socials. PUF, Paris.

Rossetini SM O 1985. Contágio no consultório odontológico: como entender e prevenir. Santos, São Paulo.

Sida/Aids 1986. Recomendações para hospitais, ambulatórios médicos, odontológicos e Laboratoriais. Centro de Documentação do M inistério da Saúde, Brasília.

Silverman Jr. S 1991. AIDS update: oral manifestation and management. The dental clinics of $\mathrm{N}$ orth America: infection control and office safety 35(2):259-268.

Souza Filho EA 1998. A abordagem estrutural das repre sentações sociais, pp. 215-236. In ASP M oreira \& DC Oliveira (org.). Estudos interdisciplinares de representação social. AB, Goiânia.

Spink MJP \& Gimenes M GG 1994. Práticas discursivas e produção de sentido: apontamentos metodológicos para a análise de discursos sobre a saúde e a doença. Saúde e Sociedade 3(2):149-169.

Artigo apresentado em 19/12/2003

Aprovado em 15/04/2004

Versão final apresentada em 3/09/2004 